\title{
Representación religiosa en la tradición oral de la provincia de Pasco
}

\section{Pasku pruwinsiyaćhu limaynin yaćhayninćhu iñininta likachikun}

\section{Pokobentaigiro kemisantagantsi kara nibarintsitsa imagantsi jitacha Pasco}

Recepción: 08 febrero 2020 Corregido: 16 junio 2020 Aprobación: 29 septiembre 22020

Pablo Lenin La Madrid Vivar

Nacionalidad: Peruana

Filiación: Universidad Nacional Daniel Alcides Carrión

Correo: plamadridv@undac.edu.pe Orcid:0000-0003-0330-0220

\section{Resumen}

En este artículo se tiene como objetivo explicar las representaciones religiosas en la tradición oral de Pasco, a partir de las narraciones orales recogidas en los trece distritos de la provincia de Pasco. Por ello se trabajó con la entrevista como método de investigación, se recogió la información in situ, en los distintos pueblos que conforman la provincia de Pasco, de manera directa de los ancianos y otros informantes. El estudio se encuentra dentro de las Ciencias Sociales, cuyo resultado fue la publicación del primer tomo de la tradición oral de Pasco. El resultado de la investigación nos ofrece cuentos y leyendas inéditos que van a configurar el panorama literario de Pasco.

\section{Palabras clave:}

Tradición oral; Religión;

Cuentos; Leyendas.

\section{Lisichiku limaykuna:}

limayćhu yaćhaykuna; Iñiy; Willakuykuna; Lihintakuna.

\section{Nibarintsipage}

katingatsaro: nibarintsitsakë; kengabagetagantsi, kengagantsitsa

\section{Religious representation in the oral tradition of the province of Pasco}

\begin{abstract}
The objective of this article is to explain the religious representations in the Pasco oral tradition, based on the oral narratives collected in the thirteen districts of the Pasco province. For this reason, the interview was used as a research method, the information was collected in situ, in the different towns that make up the province of Pasco, directly from the elderly and other informants. The study is within the Social Sciences, the result of which was the publication of the first volume of Pasco's oral tradition. The result of the investigation offers us unpublished tales and legends that will shape Pasco's literary prospect.
\end{abstract}

\section{Keywords}

Oral tradition, religion, stories, legends. 


\section{Representação religiosa na tradição oral da província de Pasco}

\section{Resumo}

Em este artigo o objetivo é explicar as representações religiosas na tradição oral de $P a s c o$, a partir das narrações orais coletadas nos treze distritos da província de Pasco. Por isso, trabalhou-se com a entrevista como método de pesquisa, as informações foram coletadas in situ, nos diferentes municípios que compõem a província de Pasco, diretamente dos idosos e de outros informantes. O estudo insere-se dentro das Ciências Sociais, cujo resultado foi a publicação do primeiro volume da tradição oral de Pasco. O resultado da investigação nos oferece histórias e lendas inéditas que moldarão o panorama literário de Pasco.

\section{Palavras-chave:}

Tradição oral, religião, histórias, lendas.

\section{Datos del autor}

Pablo Lenin La Madrid Vivar es docente e investigador en literatura y educación. Magíster en Docencia en el Nivel Superior por la Universidad Nacional Mayor de San Marcos. Autor del libro Poesía sin palabras. 


\section{Introducción}

Pasco es una de las veinticuatro regiones del Perú, está conformado por tres provincias; Pasco, Daniel Carrión y Oxapampa. La provincia de Pasco tiene trece distritos: Chaupimarca, Yanacancha, Simón Bolívar, Yarusyacán, Pallanchacra, Huariaca, Ticlacayán, Ninacaca, Huachón, Tinyahuarco, Paucartambo, Vicco y Huayllay; es en estos distritos donde realizamos la investigación de recolección de la información de la tradición oral de Pasco. Las narraciones de los informantes fueron de manera oral, sus testimonios dieron fe de sus tradiciones y costumbres religiosas, agrícolas, sociales, festivas, ganaderas, supersticiosas y demás. La investigación de campo se realizó entre los meses de abril a noviembre del año 2019, meses en los cuales los investigadores, todos ellos profesores de la facultad de Ciencias de la Educación de la Universidad Nacional Daniel Alcides Carrión, David Salazar Espinoza, Teófilo Valentín Melgarejo, Elsa Muñoz Romero y Pablo La Madrid Vivar, visitaron los trece distritos de Pasco con el propósito de recoger la información pertinente. Se entrevistó a más de cuarenta pobladores, como no recordar a Roy Palacios Ávalos, quien nos contó por qué a los pallanchacrinos les Ilaman segrachaquis y la historia de los milagros del tayta Nashaco, a Guzmán Torres Grados, que nos narró los orígenes de Ticlacayán y la bella durmiente de Ticlacayán, al viejito Hipólito Robles oriundo de la comunidad campesina de Cochacharao (distrito de Yarusyacán), anciano Ileno de historias hermosas y que nos narró historia del niño San Francisco, y el supay y el pescador, entre otras, también recordar a don Porfirio Jaime Alpas natural de Huariaca, quien nos contó de por qué denominan a los huariaqueños huascasuas. Estos y otros pobladores de los distritos de la provincia de Pasco han relatado maravillosas historias inéditas en los estudios e investigaciones de la tradición oral de Pasco. En tal perspectiva afirmamos que nuestra investigación en el campo académico de la literatura es un estudio inédito, no solo porque recoge cuentos, leyendas, y anécdotas nuevas en el espacio literario, sino también porque fortalece el estudio de la tradición oral del pueblo de Pasco y a la vez permite su configuración cultural en el espacio nacional e internacional.

La presente investigación rescata de la cultura popular el conocimiento ancestral del pueblo pasqueño en estos tiempos del dominio de la imagen y de la escritura a través de la tecnología. La investigación evidencia que todavía existen cuentos, leyendas, mitos e historias por descubrir. El imaginario colectivo nos ha permitido reconstruir los discursos mágicos de todo un pueblo. "La tradición es, pues, un elemento necesario de toda cultura en tanto forma organizada de vida de un grupo multigeneracional humano, sellado por un estilo vital propio" (Sambarino, 1980, p. 122), en tal sentido las costumbres de los pueblos tienen sus propias características de acuerdo con el contexto propio de cada zona geográfica, características que son parte de la idiosincrasia de la cultura de un pueblo y que se ponen de manifiesto mediante la oralidad de generación en generación.

La tradición oral está arraigada en el pensamiento de las masas que la preservan con mucha pasión, así la tradición oral transmite ese arraigo pasional en sus cuentos, mitos, leyendas, anécdotas y demás historias. Con el propósito de que no se pierdan y puedan ser reconocidas en el ámbito social y cultural de los pueblos. Un claro ejemplo de ello es la tradición oral judía, pueblo que por más de dos mil años conserva sus tradiciones y costumbres. La oralidad fue el insumo principal en el origen de los textos sagrados, a los primeros profetas, la palabra oral de Dios les reveló las historias que iban a narrar a través de la inspiración divina, para que inspirados, puedan escribir las historias sagradas. Es decir, que la palabra divina creó la tradición religiosa judía, la fuente oral fue la génesis de la cultura judía. La tradición religiosa judía nace de la oralidad de Dios. "Toda la Escritura proviene de la tradición, y la Escritura sin tradición 
oral no existe. La transmisión oral precede, acompaña y sigue las Sagradas Escrituras [...] En el judaísmo, la Biblia no es un texto desnudo, sino un texto ya vestido de toda la parafernalia de la tradición oral" (Manns, 2014, p. 221). La memoria ágrafa del pueblo judío supo transmitir magistralmente su cultura a lo largo de dos milenios, y todo gracias a su sólida creencia religiosa de tradición oral, que supo construir a través de sus profetas la idiosincrasia judía tal como lo señala Goya (2002):

Debido a los avateres (sic) de su historia, el judío profundamente religioso sabe que nada en este mundo es auténticamente fidedigno; sólo la Palabra de Dios le merece la estima suficiente como para confiarle todo su asentimiento. No es otra la razón por la que los judíos prefirieran, desde el principio, definir su historia, localizarla en un momento, situarla dentro de unos márgenes lo suficientemente concretos como para que no sufriera grandes transformaciones: toda la Ley transmitida en un lugar, en un momento y a un destinatario precisos: en el monte Sinaí, a un judío llamado Moisés, en representación del pueblo escogido. (p.110).

\section{Religiosidad en la tradición oral de la provincia}

\section{de Pasco}

Ante los fenómenos naturales inexplicables y experiencias fuera del orden lógico los hombres antiguos buscaron respuestas a dichos fenómenos y experiencias y sobre todo ante la incertidumbre frente a la muerte. La mayor respuesta fue creer en un ser divino y superior que está fuera del alcance de los hombres mortales. Así, Dios aparecía en las religiones del mundo, aparecía como salvador. Han transcurrido de ello miles de años y el panorama parece ser la misma frente a la pandemia devastadora que vive la humanidad, en estos momentos, por la covid-19, creer en un salvador, la creencia en un Dios a través de la religiosidad de los seres humanos, fue y es la única esperanza a las preguntas que la ciencia todavía no puede ofrecer. La religión como fenómeno social se divorcia de la razón para dar paso a la fe, es la fe la que mueve a los humanos a creer en lo increíble. Es lo ideal en un mundo real, que, proyecta ocultamente esperanzas ante lo desconocido, la esencia humana tiende a creer en algo y en alguien que lo ayude a salir de sus problemas. La experiencia personal de cada individuo motiva a escoger o no la religión como código de vida, no obstante, para los pueblos antiguos creer en los dioses era una necesidad de vida, sus pensamientos y acciones religiosas construyeron grandes imperios. Este pensamiento religioso fue transmitiéndose de generación en generación y de pueblo en pueblo hasta fijar en sus consciencias que existe un ser superior que rige los destinos de los hombres y del mundo. Posiblemente los antiguos habitantes de Pasco no estuvieron exentos de este proceso religioso y fue así como su creencia religiosa fue transmitiéndose oralmente hasta determinar el contexto religioso pasqueño, que, hoy son narrados por la memoria ágrafa del poblador pasqueño.

Las historias religiosas en los pueblos de Pasco siempre han estado presentes en su tradición oral como acto de fe ante los problemas de su entorno, en las culturas pre hispánicas con la creencia en varios dioses y con la llegada de los españoles el tema religioso se circunscribe al catolicismo en la que Dios está presente como el ser que mueve el destino de los hombres.

Como afirma Habermas, la idea de un acercamiento al Reino de Dios, idea que permanece dentro de los límites de la mera razón, despierta en nosotros la consciencia de una responsabilidad colectiva frente a las carencias y falencias de nuestro orden social y del desarrollo 
histórico, y constituye, por lo tanto, una especie de protesta contra la contingencia del destino social y contra el caos del mundo material. (Mansilla, 2007, párrs. 9).

Los hechos religiosos, durante la investigación, fueron narrados en cuentos, leyendas, o rituales, lo atípico fue que durante el estudio no se recogió cantos religiosos. El tema religioso como proceso socio espiritual se mantiene por la fe de la población, pese a los avances científicos, estos hombres y mujeres mantienen su creencia en Dios. Nuestros informantes, en el desarrollo la investigación, siempre mostraron su fe religiosa que se pudo observar en sus comportamientos y actitudes. Para ellos la religión es una norma ética que les permite convivir en armonía y en paz. "Lo rescatable de la religión y aun de la mística para el mundo de hoy debe ser visto en algunos elementos que son comunes a todos los credos y que han estado inextricablemente unidos a un concepto profundo de lo teológico: el respeto absoluto a la vida, el mandamiento del amor y la ética de la reciprocidad" (Mansilla, 2007, párrs. 15).

El pueblo pasqueño se ha identificado como un pueblo históricamente religioso sus costumbres están ligadas a la religiosidad, citamos como ejemplo la fiesta del distrito de Santa Ana de Tusi, una de las fiestas más grandes de Pasco, en honor a la madre Ana, abuela de Jesús; la fiesta de San Pedro y San Pablo en el distrito de Ticlacayán, la fiesta en honor a San Pedro en Yanahuanca, capital de la provincia Daniel Carrión, la fiesta de las cruces de mayo en la ciudad de Cerro de Pasco, en honor al señor Jesucristo, la fiesta en homenaje al señor de Ancara en el distrito de Paucartambo, otra de las fiestas grandes de Pasco. En estas fiestas atender al visitante es una obligación moral, la reciprocidad ancestral todavía pervive en las fiestas costumbristas pasqueñas, así durante el mes de mayo da cada año el pueblo de Pasco rinde homenaje a tayta Cristo que en la tradición religiosa pasqueña tiene diversos nombres: Señor de San Cristóbal, Señor de Huancapucro, el tayta Caña, Señor de Uliachín, el Señor de Exaltación, San Atanacio; el homenaje se realiza con la fiesta denominada Cruces de Mayo, la fiesta reúne a la población en su conjunto en donde se bebe el famoso 'Shinguirito' (licor producido con aguardiente, azúcar y remedios caseros), los mayordomos devotos de las imágenes de Cristo brindan comida y trago a la población. Para poder organizar la fiesta de mayo los mayordomos de la fiesta religiosa solicitan el socorro económico de sus familiares y amigos, quienes brindan el apoyo con la condición de ser devuelta en su momento, este costumbre se conoce como 'Huashca', que significa hoy yo te ayudo y mañana tú me ayudas, el aporte económico o material se devuelve en un tiempo prudencial, ello refleja que la reciprocidad andina pervive aún en la tradición pasqueña. Está costumbre no es moderna, las culturas prehispánicas ya lo practicaban, así Alberti y Mayer (1974) lo sostienen:

Generalmente el curaca es el jefe de una familia muy extensa, quien, basado siempre en el principio de reciprocidad, retribuye las prestaciones recibidas por su numerosa parentela cumpliendo funciones distintas y muchas veces simbólicas, como asegurar la paz interna, organizar los ritos religiosos, velar por la redistribución de los productos a los huérfanos (waqcha), a los que no tienen familia en la comunidad, etc. La importancia del curaca en la organización económica del imperio radica en su capacidad de movilizar a la población para los trabajos requeridos por el Estado. El principio de reciprocidad, que regula la vida social del ayllu también rige las relaciones entre el ayllu y el Estado Inca. (p. 17).

La investigación ha evidenciado que la religiosidad como acto de fe y salvación está presente en el pueblo pasqueño, encontramos en el distrito de San Miguel de Pallanchacra la historia del tayta Nashaco que frente a la sequía es sacado a la puerta principal de la iglesia para que con su bendición otorgue la lluvia, asimismo, en este distrito se narra la aparición de San Miguel, quien juega con un niño a quien dice donde quiere que se construya su iglesia. 
Esta misma historia es contada en el distrito de San Francisco de Asís quien también juega con un niño y le pide donde construir la iglesia. La historia de San Miguel y San Francisco es un proceso de aclimatación, tal como lo sostiene Arguedas (1987): “Un interés especial ha atentado a los folkloristas en sus estudios del cuento: el origen, es decir, la procedencia del tema; La difusión de esos temas. ¿En qué otros cuentos de los demás países del mundo figuran esos temas? ¿Cómo, por cuáles vías se han difundido dichos temas? ¿Qué transformaciones o "aclimataciones" han sufrido al ser incorporados en el repertorio particular de cada pueblo?" (p. 89). Otro personaje religioso es el padre Cuto Vitula, sacerdote que ordena la construcción de la iglesia de Pallanchacra y de cómo valiéndose de su cargo misionero aprovecha para tener comercio carnal con una mujer del pueblo. La fe se expresa en la creencia de lo irracional convertida en racional mediante el significado que el hombre otorga a lo sagrado de su creencia. $Y$ con fe todo se puede, reza el dicho, que los pueblos lo han asimilado a lo largo de su ciclo vital, movido por esta fe don Hipólito Robles nos contó que los yarusyaquinos ganaron el pleito judicial que tenían con la comunidad de Cajamarquilla por terrenos, gracias a la intervención de la Virgen María y de San Francisco de Asís.

La Virgen Inmaculada es la patrona del distrito de Vicco, también ordena el lugar donde será construida la iglesia, y manda a no ser movida de la iglesia, pero al ser sacada para la procesión se produce una tormentosa lluvia con granizos rojos, por lo que los viqueños tuvieron que crear una réplica de la Virgen para que sea esta la que acompañe las procesiones, así la imagen original nunca más volvió ha salir en procesión. Lo mismo ocurre en el distrito de Ninacaca, el patrono San Pedro, ordena que no debe ser bajado del altar mayor por ningún motivo, sin embargo, la población desobediente baja la imagen y se produce una lluvia con granizos rosados. El proceso de aclimatación se presenta nuevamente en estos dos cuentos. En el distrito de Ticlacayán aparece San Pablo como guía y patrono del distrito, asimismo en el distrito de Huachón la Virgen María es la defensora de los indefensos indios.

En términos generales, entendemos a la religiosidad popular como manifestaciones de formas de ser, de estar y de expresar una vinculación con lo sagrado [...] que remiten a búsquedas de reconocimiento, de identidad y de transformación. Así, desde esta perspectiva, la religiosidad de los sectores populares expresa por un lado la diversidad de sentidos e identidades socioculturales de aquel colectivo que tiende a ser nombrado como "pueblo", rescatando a su vez su “agencia”, sus anhelos y esperanzas. (López, y Suárez, 2016, párrs, 4-5).

El pueblo en su sabiduría aguarda con esperanza la solución a sus múltiples problemas de salud, económicos, familiares o de otra índole, esperanza que se espera con fe religiosa, la que ayuda a sobrellevar los problemas con estoicismo, al margen del escepticismo de algunos o de la consideración de los marxistas de que la religión es la enajenación del hombre.

\section{Sincretismo religioso y supersticioso}

Antes de la llegada de los españoles las culturas prehispánicas peruanas, entre ellas, la inca, tenían sus propias creencias, costumbres, mitos, leyendas y sus dioses inherentes a su cosmovisión del mundo propias de sus costumbres y creencias. La mentalidad indígena crea una mitología propia, natural con el mundo que percibían y vivían; con personajes que simbolizan los fenómenos y hechos del universo; y emblemas de carácter ideográfico, que tienen una significación determinada. "En mitos, leyendas, fábulas y otras formas de expresión deja cristalizada su sabiduría, su peculiar manera de explicar los fenómenos tangibles e intangibles, y ellos forman otra rica fuente de apreciación del pasado". (Carrión, 2005, p. 20). 
Así, el rito a las huacas era un acto ínsito del poblador prehispánico, el masticado de la coca era necesario como fuente de energía, el oráculo de la coca adivinaba el porvenir de la gente, la celebración al dios-sol; al dios hacedor Viracocha, al dios rayo Libiac, entre otros, mostraba el politeísmo de los pueblos anteriores a los occidentales; con la llegada de estos se trastocó la concepción politeísta a una monoteísta, a un solo dios, pero la evangelización y la destrucción de las idolatrías no logró destruir por completo el politeísmo prehispánico. Aún subsisten algunas costumbres como el rito a la coca, el pago a los cerros, al tributo a la Pachamama, costumbres ancestrales enraizadas en el pensamiento moderno del hombre andino y que al fundirse con la tradición religiosa occidental se produce el sincretismo religioso y supersticioso que constituye la fe religiosa contemporánea de los hombres pasqueños. Al trastocarse la primitiva creencia religiosa de los pueblos prehispánicos a raíz de la evangelización occidental de la época colonial, se inició el sincretismo religioso en el Perú, al respecto Marzal (1983) nos dice:

Tal transformación se da en la población del Tawantinsuyu como conjunto, aunque no del mismo modo, ni en todas y cada una de las etnias costeñas y serranas, por la aceptación de un conjunto de creencias, ritos, formas de organización y normas éticas de origen cristiano, sin que por ello muchos indios, sobre todo de la región surandina, hayan dejado de conservar e integrar elementos de su viejo sistema religioso andino, para conformar un sistema más o menos sincrético (Introducción, p. 10).

Sin embargo, el sincretismo religioso no fue la solución que los curas occidentales esperaban, no fue un fenómeno consumado en su momento. Los pobladores nativos de América no aceptaron convincentemente al nuevo dios que les imponían de una forma autoritaria, muchos continuaron clandestinamente adorando a sus propios dioses y peor aún hubo quienes muy perspicazmente percibieron algunas incoherencias en el discurso religioso de la doctrina cristiana, así el padre Marzal (2005) nos refiere que en el sermonario de 1585 un indio realiza la siguiente pregunta: "Padre, ¿cómo nos decís que no adoremos ídolos, ni guacas? ¿Pues los cristianos no adoran las imágenes que están pintadas y hechas de palo, de metal, y las besan, y se hincan de rodillas delante de ellas, y se dan en los pechos, y hablan con ellas? ¿Estas no son guacas también, como las nuestras?" ( $p, 16)$. En el proceso de sincretismo religioso no se debe perder de vista la reciprocidad andina como acción solidaria de socorrer al prójimo, practicado desde antes de la conquista, y que constituye una de las características de la religión andina.

La Minga es la principal instituci6n de reciprocidad indígena y se constituye como una de las bases fundamentales de la organizaci6n social andina. Consiste en el aporte de trabajo mancomunado y solidario de todos los miembros de un grupo social, con el fin de ejecutar una obra de interés común. La Minga perdura en muchas comunidades como un ritual y ceremonial de convocatoria y cohesi6n de los pueblos, su participaci6n masiva y colectiva permite mantener los intereses de la comunidad en medio de una expresión plena de solidaridad y de redistribuci6n interna y auto centrada de bienes y servicios (De la Torre y Sandoval, 2004, p, 29).

La reciprocidad andina como valor cristiano es propia de las culturas prehispánicas, sin necesidad de una teología católica. El sincretismo religioso, iniciado en la colonia, ha ido con el tiempo adquiriendo su propia identidad y está presente en la tradición oral de Pasco y seguramente en la tradición oral de muchos pueblos latinoamericanos, un claro ejemplo es el cuento los milagros del tayta Nashaco relatado por Roy Palacios Ávalos en el distrito de Pallanchacra, donde por la sequía la imagen del cristo nazareno es colocado en la entrada de la iglesia para que la imagen realice el milagro de la lluvia, antes de dicha ceremonia religiosa los pobladores de Pallanchacra realizan el rito del famoso "boleo", es decir, mastican la coca produciendo 
con ella una bola dentro de la boca. Otro ejemplo del sincretismo religioso sostenido por la iglesia católica es la denominación de los distritos y pueblos del Perú, hecho atribuido a los evangelizadores españoles, por lo que los distritos se denominan San Miguel de Pallanchacra, San Francisco de Asís de Yarusyacán, San Pedro de Pillao, Santa Ana de Tusi, etc. Este hecho es relevante porque permite conocer que las culturas prehispánicas en su sapiencia habían denominado a sus pueblos de acuerdo con la toponimia pertinente y que los extranjeros al no poder eliminarlos vieron por conveniente adicionar un nombre cristiano, el de los santos y religiosos, no solamente con el propósito religioso, sino también de dominación.

\section{Historias religiosas recogidas enlainvestigación}

\section{Los milagros del tayta Nashaco}

Hay tiempos en que la sequía llega a Pallanchacra', entonces se afecta la agricultura y ganadería, entonces la gente por costumbre saca a una imagen de la iglesia al cual le llamamos tayta $\mathrm{Nashaco}^{2}$, en sí es el padre nazareno, es la figura de cristo, es una imagen antigua; ya está un poco deteriorado y ha sido reemplazado por otro, pero está cumpliendo su función de hacer milagros.

El tayta Nashaco, es sacado a la puerta de la iglesia y la población le pide con mucha devoción el milagro de que llueva para que haya agua y la cosecha no se pierda, ni se mueran los animales. Y parece mentira, pero a los pocos días comienza a llover e incluso a granizar. Entonces la población grita ¡Milagro, milagro!

Pero antes del milagro, la población hace su boleo de coca. Hacen bastantes boleos, incluso le ponen cigarro al tayta Nashaco y también sal. Traen dos Baldes grandes, a uno le Ilaman "agua yanayaco" y al otro balde le llaman "yacuyuraj"3, porque las aguas de un balde son negras y del otro, blancas; entonces le ponen coca y toda la sal y con ello, como pago, se van a la laguna de Ñahuicocha4. Una comisión realiza el pago en esa laguna echando la sal a la laguna. Luego pasa todo ese asunto y no pasa dos días y empieza el gran diluvio, se viene la Iluvia hasta que afecta las casas; tanto que cuando le miran el rostro del tayta Nashaco está mojado con toda su vestimenta por lo que la población saca los capotes que usan los mineros y fabrican una pequeña casa para protegerlo mientras dura la lluvia, durante ese tiempo el tayta Nashaco es vestido como minero.

Si la lluvia persiste, entonces necesariamente tienen que hacerlo regresar a la iglesia, porque a veces la abundancia del agua afecta el sembrío. Esta costumbre se da hasta el día de hoy, es un rito casi pagano entre la fe católica y la costumbre popular del pueblo, ya que la devoción cristiana se mezcla con la práctica del boleo de coca, con el ritual de la sal que es obligatorio. El boleo de coca de las personas es recogido por la comisión, quienes lo arrojan a la laguna, y ni bien echan la sal a la laguna el lugar se pone anublado. La iniciación de este rito es muy especial para las autoridades y lo inicia el padre de Huariaca que autoriza la salida del tayta Nashaco.

\footnotetext{
1 Testimonio: Roy Palacios Ávalos, registrado en Pallanchacra, junio de 2019.

2 El tayta Nashaco, es el Cristo Nazareno. Su figura se encuentra en la iglesia del distrito de Pallanchacra con un hábito morado.

3 Término quechua que en castellano significa agua blanca o agua limpia.

4 Término quechua que significa ojo de laguna.
} 
Como le vuelvo a decir, el rito es algo especial, las autoridades convocan a la población, tocan la campana de la iglesia para que el pueblo sepa el comienzo de la lucha contra la sequía. Se dirigen a la laguna Ñahuicocha (ojo de la laguna) donde gritan fuerte sus plegarias manifestando que sus suelos, sus sembríos y sus ganados se están muriendo por falta de agua. Entonces el padre le da la bendición a la laguna para que suelte la lluvia y en ese momento de verdad, cuando echan la sal, empieza a aparecer la neblina. El cielo azul se pone gris5. Las plegarias lo hacen en quechua, luego vuelven para el pueblo y se reúnen de alegría y empiezan a jugar con la imagen del tayta Nashaco, le ponen guantes, le ponen chalina, y por último le ponen muy bien su cigarrillo. El milagro se hace realidad.

\section{El padre Cuto Vitula}

Los jesuitas y los franciscanos ${ }^{6}$, recorrieron todo el territorio peruano fundando parroquias e iglesias con el propósito de salvar las almas de los indios, quienes, según los curas, no creían en el dios cristiano todo poderoso. Uno de estos curas llamado Cuto Vitula llegó a PaIlanchacra y al ver el pequeño templo construido de manera artesanal con tierra y paja decidió construir una nueva iglesia y así fue. Con ayuda de los pallanchacrinos construyó toda la iglesia actual de Pallanchacra, lo ha remodelado para que los campesinos vayan a escuchar misa.

El padre Cuto Vitula era famoso por su carácter dictatorial, intolerante y abusivo. El poblador o pobladora que no iba a la misa pagaba una multa, el pago de castigo era el huevo de tres gallinas por semana o una canasta llena de huevos. Obligaba a la población a asistir a misa en las mañanas y en las noches, dos veces por día. Cada mañana tocaba la campana de la iglesia. Y la gente estaba obligado a ir a misa antes que ir a sus chacras o hacer varios trabajos. El pueblo tenía que estar bien evangelizado, decía. Cualquier acto de incredulidad era castigado, el que lo desobedecía, era señalado con el dedo; le fijaba con la mano, era como una sentencia. El castigo de la sentencia era ir a misa por un mes completo para que Dios le bendiga.

Tanto fue el carácter intolerante del padre Vitula que el pueblo se cansó y se sublevó contra el curita. Y un día se pusieron de acuerdo que no irían a misa y no fueron. El cura esperaba en vano a la población, al ver la iglesia vacía empezó a gritar contra los campesinos, a maldecirlos. Fue de casa en casa a llamarlos y observó que las mujeres se dedicaban a cocinar en vez de ir a misa. Entonces el curita desesperado salió de su iglesia con sus ayudantes y feligreses, cada uno de ellos con un balde de agua y fueron a las casas de las campesinas donde entraban sin pedir permiso y arrojan el balde agua en las bicharras de las mujeres ${ }^{7}$, para obligarlas a ir a la iglesia, apagaban las cocinas de las pobres campesinas. Las asustadas mujeres no sabían que hacer porque no podían cocinar y por lo tanto no podían llevar el almuerzo a la chacra donde trabajaban sus esposos. Una vez apagado las bicharras, obligaba a las mujeres a ir a misa. Mientras tanto no llegaba el almuerzo y todo renegado los campesinos regresaban a casa a reclamar a sus esposas, algunos de ellos dieron golpe a sus mujeres. Las pobrecitas avisaron a sus esposos lo que el curita hacía con las bicharras y lo que les decía: "nadie cocina porque todos tienen que ir a la misa" y como es nuestro santo padre tenemos que hacerle caso. Tal es así que la gente se amargó y los pobladores acordaron hacer una marcha, una manifestación hasta lograr botar al cura de Pallanchacra. Pero antes que se vaya, el padre Vitula subió a la plaza y dio su palabra y maldijo a Pallanchacra: "Que venga todas las maldiciones del diablo

\footnotetext{
5 Las nubes invaden el cielo soleado para dar paso a la lluvia y esto gracias al rito costumbrista del pueblo pallanchacrino.

6 Testimonio de Roy Palacios Ávalos, registrado en Pallanchacra en el 2019.

7 Cocina hecha a base de barro.
} 
para Pallanchacra", dijo el curita, porque están votando a un padre de Dios, a su representante más cercano sobre la Tierra. Y desde ese día los pallanchacrinos creen que hay un egoísmo entre ellos y por eso muchos no progresan, además creen que es la causa de la baja producción en la chacra, además de la llegada de las plagas y de la baja calidad de las jaramishas que ya no tienen el tamaño de antes.

\section{San Miguelito}

Pallanchacra ${ }^{8}$, está ubicado en la zona de Huacati y Pallanchapata, en esos lugares hay restos de construcciones antiguas. Los pastores venían a este lugar porque era un oconal listo para la ganadería.

Antiguamente, un pastorcito de Pallanchacra se demoraba mucho en llegar a su casa y sus padres se habían preocupado porque no llegaba su hijo, esto sucedía en varias oportunidades, aparecía muy noche mientras las ovejas llegaban temprano. Entonces su padre fue a vigilar a su hijo y se dio con la grata sorpresa que estaba jugando con un niño de piel blanca, el cabello rubio y ojos azules. El campesino apareció de sorpresa ante los niños que jugaban distraídamente, el niño rubio corrió, se zafó por los matorrales y desapareció; su hijo le contó que era un niño que se hacía llamar San Miguelito y que no sabía de dónde venía. Pero que siempre estaba en ese lugar y que jugaba con él.

Al día siguiente, el pastorcito de nuevo se puso a jugar con San Miguelito, y el padre nuevamente fracasó en el intento de atraparlo. Esa noche el pastorcito soñó que San Miguelito le decía que su papá lo había sorprendido y le pidió que lo ayudara a construir su templo. El niño le contó sus sueños a su papá. El hombre convocó a una reunión a los pobladores y le narró todo sobre San Miguelito. La gente acordó ir a lugar y encontraron una imagen de San Miguel.

Entonces todos los habitantes del lugar se pusieron de acuerdo de construir una capilla arriba en Pallanchapata (pallan es recoger productos) y (pata es un lugar de arriba de altura). Hicieron la capilla dónde depositaron la imagen de San Miguel, pero sucedió que la imagen constantemente desaparecía del lugar, no permanecía ahí, huía la imagen. Tal es así que otra vez lo encontraban jugando con los niños en aquel mismo lugar. San Miguel empezó a revelar a los comuneros en sus sueños dónde quería permanecer y fue en el manantial donde se ubica la iglesia actualmente; pero en esa época, todo ese lugar era un oconal, justamente dónde hoy día es la plaza principal de Pallanchacra. Este lugar estaba invadido de agua, era una zona de manantiales. Los comuneros se preguntaban cómo van a construir la iglesia en medio del manantial. La gente no quiso construir la iglesia en medio del agra e incluso hubo un poblador que azuzó a los demás pobladores para no construir la iglesia, se negó rotundamente. A este poblador se le apareció San Miguel en sueños y no hizo caso de los sueños. Entonces sucedió que sus ganados, sus productos de la chacra ya no rendían frutos, recién se convenció que debían construir en el manantial la iglesia para San Miguel. Hicieron la capilla de la iglesia en el oconal, para eso canalizaron todas las aguas del oconal. Necesitaban de un terreno libre de agua, y los comuneros trabajaron fuertemente. Sucede que desde esa fecha empiezan los pallanchacrinos a tener fe en san miguelito, por lo que más adelante denominan al pueblo San Miguel de Pallanchacra.

8 Testimonio: Roy Palacios Ávalos, registrado en Pallanchacra en el 2019 


\section{El rabo de mula del padre Vitula}

Antiguamente Pallanchacra era un pueblo con poca gente, ${ }^{9}$ los pobladores que vivían en esos años no tenían donde rezar y donde rendir culto a Dios. Por las noches, luego de llegar de las chacras donde trabajan sembrando la papa, el maíz y algunas hortalizas, se encerraban en sus chozas sin saber a dónde ir.

Los hombres realizaban la misma rutina todos los días, la de ir a las chacras, lo mismo las mujeres que se dedicaban a juntar leña y cocinar para sus hombres. Por aquellos años llegó el cura llamado padre Vitula quien compró la hacienda de Conoc; luego, al enterarse de que no había una iglesia, convocó a los pocos pobladores y con un sermón los obligó a construir la iglesia. En el día supervisaba la obra y por la noche regresaba a Conoc y al no tener quien le haga el servicio de su atención, contrató a mi abuelita como su empleada. Mi abuelita le servía y atendía al padre. En agradecimiento, el padre Vitula le regaló un terrenito que queda en el antiguo cementerio y allí mis abuelos hicieron su casa donde hoy vivimos.

Mi abuelita vendía huevos con leche por orden de su mamá, una tarde fue a vender a casa del padre Vitula. Tocó su puerta y nadie respondió, como tenía que vender insistió y se fue a tocar la ventana; en eso vio al padre Vitula calato, que se abrazaba con una mujer, estaban echados en la cama. Por las posaderas del padre aparecía una cola de mula. Mi abuelita vio claramente la cola de mula que tenía el padre Vitula. Temblorosa, se fue corriendo para su casa, al llegar le contó a su mamá que en el poto del cura había una cola llena de pelos negros. La mamá de mi abuelita se persignó y cuando amaneció contó a las personas sobre la cola del cura Vitula. Al principio no creyeron que el cura tuviera rabo de burro. Pero al pasar los meses, la mujer que vivía con el padre Vitula parió varios hijos, recién en ese momento creyeron que tenía un rabo.

El cura se negó a darle su apellido a sus hijos. La población empezó a murmurar, el Vitula se enteró que la gente hablaba a sus espaldas y aprovechó la misa para insultar a los que hablaban su mal. El cura decía que los hijos son la bendición de Dios. En eso la mamá de mi abuela se paró y le preguntó si en su poto tenía rabo de mula, todos se rieron. El padre Vitula, muy furioso, botó a la mamá de mi abuelita de la iglesia y terminó bruscamente la misa. Desde aquel día los pallanchacrinos riéndose cuentan del rabo de mula del cura.

Hoy que han pasado más de cincuenta años, los hijos del padre Vitula son empresarios en Cerro de Pasco, pero con otro apellido.

\section{El supay y el pescador}

Cuando yo era niño, mi abuela me contó que en Cochacharao, ${ }^{10}$ vivía un señor con sus hijitos y su esposa, eran muy pobres, lo que trabajaba en la chacra no le alcanzaba para nada. El padre era un experto en pescar, por lo que la gente le conocía como "el pescador". Iba todos los días a truchar al río Tingo, mi abuela decía que en ese tiempo el río no estaba contaminado y que abundaban las truchas.

9 Testimonio; Andrea Paulino, registrado en Pallanchacra en el 2019.

10Testimonio; Hipólito Robles, registrado en Cochacharao (Yarusyacán), junio de 2019. 
Un día que estaba truchando, el pescador se queda dormido en la orilla del río. Después de un rato despierta y se da con la sorpresa que ya no estaba en la orilla, se encontraba en otro sitio. El pescador se dice: ¿qué pasó’, ¿dónde estoy?; en eso aparecen varias mujeres rubias.

- Estas gringas son guapas y altas, son gente grande - Dice el pescador.

Y de un momento a otro llega un hombre alto, ${ }^{11}$ con bigotes muy negros y le dice al pescador:

- Bienvenido a mi humilde hogar.

- ¿quién eres tú?, ¿quiénes son aquellas señoritas? - dice asombrado el pescador.

- Son mis hijas - le responde el hombre alto - en cuanto a mí, después te diré quién soy.

Luego ordena a una de sus hijas que atienda al hombre. La mujer le brinda comida y ropa. Todo el día es atendido por las chicas rubias. Al anochecer el pescador quiere regresar a su casa. Entonces el hombre de bigotes negros le pide su anillo viejo para dejarlo ir y le dice que tiene que volver si es que quiere recuperar su anillo, para eso tenía que quedarse dormido nuevamente en la orilla del río. El pescador cierra sus ojos y aparece en la puerta de su casa. Su familia lo mira sorprendida, se entera que había estado un año fuera de su casa, pero él afirma que se ausentó solo por un día. Después de varios días el asunto se olvida y todo vuelve a la normalidad.

Mi abuelita decía que pasó un mes y nuevamente el pescador se queda dormido cerca del río Tingo, apareciendo otra vez en la casa del hombre alto que le dice:

- Muy bien, cumpliste con tu promesa de regresar.

Y le devuelve su anillo viejo. Una de las mujeres rubias le da piedras en forma de collotas, afirmando que son papas para su alimentación y de su familia. El hombre regresa a su casa con las piedras. Y también se había demorado un año en regresar, pero él seguía afirmando que solo se había ido un día. Su esposa y sus hijos no sabían que decir, pero se alegran al ver las papas que empiezan a comerlas, y cuando él intenta comer no puede porque en vez de papas muerde piedras, mientras su familia comía normalmente las papas.

Al día siguiente, el pescador intrigado por las piedras se duerme a propósito en la orilla del río y aparece en el lugar donde vivía el hombre alto con sus hijas rubias. El hombre extraño le dice al pescador:

- Has demostrado que eres una persona muy mala, porque los malos no pueden comer piedras y además, no te da pena abandonar a tu familia como tú lo haces. Por eso te vas a casar con una de mis hijas.

- Eso es mentira - responde el pescador - yo trucho todos los días para alimentar a mis hijos y esposa y no los he abandonado.

- No te has dado cuenta que lo has abandonado por dos años. Aquí en mi reino un día es un año. Yo soy el supay y tú serás mi yerno porque te necesito para mis planes. Vas a ir con mi hija, tu futura esposa, a mi hacienda. Allí en nuestro terreno hay bastante bosta y leña.

Mi abuela nos contaba que el pescador respondió de esta manera:

11 El diablo es conocido en la mitología andina como supay. 
- Yo tengo mi esposa, no puedo casarme con una de tus hijas.

Entonces el diablo le dijo:

- Ya que no quieres casarte con una de mis hijas, te vas a quedar aquí por treinta días. Vas a ir a nuestra hacienda con mis hijas, allí vas a cargar leña y bosta, ${ }^{12}$ en varias mulas que están allí. Solo vas a ordenar y la bosta con la leña van a subir al lomo de las mulas. Vas decir "carga leña, carga bosta" y solo se van a cargar.

- Por favor, ¿treinta días son treinta años? ¡déjame ir! Te puedo traer las mejores truchas suplicaba el pescador.

El diablo no le hizo caso y se fue. Entonces aparecen varias mulas, una de las hijas del diablo le ordena que le siga a su hacienda. Caminan cerca de una hora y llegan a la hacienda donde había bastante bosta y leña botado por todo el suelo. El pescador ordena a la bosta y a la leña que suban a los lomos de las mulas diciendo "carga leña, carga bosta" en ese momento, se da cuenta que las leñas, eran culebras muertas y secas y las bostas eran sapos muertos; le entra el miedo, la mujer lo mira y la obliga a juntar toda la leña y la bosta. Vuelven con siete u ocho mulas cargados de leña y bosta. Una de las mulas no quiere avanzar por lo que el pescador con zumbador la golpea y sucede algo inesperado, empieza a salir candela por la nariz de la mula, que dice:

- Ay compadre, usted me está castigando por gusto, no ves que estoy cansada.

El pescador asustado mira como habla la mula y no le responde. Llegan a la casa del supay quien dice:

- Pasado mañana se cumplirá los treinta días y te quedarás para siempre conmigo, a menos que hagamos una apuesta. Si tú me ganas, puedes volver a tu hogar, si pierdes, te quedas a servirme como mi esclavo. Si me ganas te llevas mi riqueza.

- Acepto - dijo el pescador.

El supay se fue y volvió con un par de botas de jebe y se lo entregó al pescador diciendo:

- Tienes dos días para que termines de gastar las botas. Esa es la prueba que te doy. Si lo logras te vas de aquí; si no, serás mi esclavo.

El hombre piensa toda la noche como gastará las botas y en cuál va a ser la prueba que él debe presentar al diablo. Mi abuela contaba que el pescador buscó un pellejo blanco, que lo pintó con anilina negra y un pellejo negro. Le muestra al diablo los dos pellejos y le dice:

- Si logras despintar uno de estos pellejos ganas la apuesta.

El diablo escoge el pellejo negro, mientras el pescador se queda con el teñido. El cochacharino va donde la mula que bota candela por su nariz y le pide que queme sus botas. Y se presenta donde el supay y le muestra las botas gastadas. Luego le dice que despinte el pellejo negro, el diablo no puede hacerlo, en cambio el pescador logra despintar su pellejo ya que era el teñido y alegre le dice:

- Señor supay, he ganado la apuesta, así que déjeme ir a mi hogar.

12Excremento seco del toro que sirve como combustible para las bicharras de los pobladores del campo del Perú. 
Yo le pregunté a mi abuelita si el diablo cumplió con su promesa y ella me dijo que sí, pero le advirtió al pescador que a nadie debe avisar que ha vivido en su casa.

- Ni a tu esposa ni a tus hijos debes decirle que me has conocido. Si lo haces yo voy a vivir para siempre en tu cuerpo. Si tú hablas mi nombre y que has vivido conmigo te va a ir muy mal - dicen que le dijo.

Antes que el pescador se vaya, el diablo le entregó una cajita como de fósforo, en la que había ceniza y le dice:

- Vas a guardar la ceniza en una ranura de tu cocina. La ceniza te va a dar producción.

Y diciendo esto le pide que cierre sus ojos. El pescador aparece de noche en su casa, toca la puerta, había vuelto después de treinta años. Sale su hijo y le dice a quién busca. Lo había desconocido, sus hijos ya eran adultos, entonces sale su esposa bien acabada y tampoco lo reconoce. El pescador entra a la casa y le cuenta que ha vivido en una ciudad lejana, entonces su esposa le reconoce se abrazan y lloran. A media noche, el pescador esconde la cajita al lado de su cocina. Al día siguiente les cuenta con mentiras dónde estuvo. Pero les muestra las riquezas que ha traído y la familia pobre se convierte en gente de plata.

El pescador era un hombre muy bueno y ayudaba a la gente que lo necesitaba. Un día, en el cumpleaños de su primo, se embriaga, se huasquea y ahí le preguntan cómo había hecho para tener mucha plata. Entre huasca y huasca les cuenta todo lo que ha pasado con el supay. Ya borracho se va a su casa y cuando llega no encuentra a nadie; sus hijos y su mujer desaparecieron, todos sus animales también. Su casa era una chocita.

Él quedó convertido en un anciano jodido, así decía mi abuela. El diablo cumplió con su promesa. Entonces el pescador andaba mendigando y murió.

\section{El niño San Francisco}

Según me contó mi abuelo el primer pueblo de Yarusyacán, ${ }^{13}$ se ubicó en la cumbre llamado Yarus. El lugar donde actualmente se siembra es Yacán, por eso el distrito se llama Yarusyacán. En esos tiempos vivía poca gente, habían hecho sus casas de tierra, la gente era analfabeta, no sabían ni escribir ni hablar castellano ni persignarse ni orar, pero así vivían pues tranquilos

La gente fue aumentando poco a poco por lo que Yarusyacán se fue poblando. Mi abuelo me dice que le contaron que en esa época una niña va a pastar sus carneritos, la chica se llama Margarita, y todos los días llegaba tarde a su casa. Su papá se molestaba con la niña el por qué no traía temprano las ovejas, siempre llegaba tarde; ya cansado, se fue a buscar a la niña a Cantopuquio (lugar, donde crecía una flor blandita al lado de un puquial. ${ }^{14}$ En Cantopuquio el hombre divisó a un niñito rubio que jugaba con su hija. El niño tenía puesto una capita, el hombre salta de su escondite y el niño desaparece, entonces la niña le cuenta a su papá que es su amiguito con quien juega y por eso se demora en llegar a casa. Le dice que juegan todo el día recogiendo leña y cuidando a las ovejas. Y cuando le invita su fiambre el niño no come. El padre intrigado se pregunta “¿Quién será aquel niño de capita?” y preocupado le dice a su hija que debe ser algún encanto.

13 Testimonio: Hipólito Robles, registrado en Cochacharao (Yarusyacán), junio de 2019.

14Lugar donde brota el agua en la tierra. 
El hombre avisa a la comunidad que donde pasta su hija hay un niño rubio con una capita que no se sabe de dónde viene, entonces la gente sale en su búsqueda. La niña va a pastar sus ovejas como de costumbre. La gente le sigue y se esconden tras algunos árboles. En eso aparece el niño no se sabe de dónde salió y empieza a jugar con la niña.

El papá de la niña se presenta de un momento a otro y sorprende a los niños en pleno juego, entonces llamó a la gente y todos salen de sus escondites. El niño se ha congelado, entonces la gente piensa que era algo de Dios. Se llevan la imagen congelada del niño a la iglesia para que lo guarden. En la iglesia, esa noche todos han chacchado coca, han fumado cigarro de alegría porque trajeron una imagen. Dejan allí al niño en Yarus Punta donde fue el primer pueblo. Al siguiente día van a verlo y no había la imagen, entonces vuelven al lugar donde lo agarraron, y allí se encontraba la imagen congelada del niño. Preocupados retornan a sus labores de pastoreo.

La niña sale con sus ovejas y se encuentra con el niño que le dice:

- Para qué me han llevado de mi casa, a dónde me han llevado, si me siguen llevando a Yarus Punta, de donde sea, voy a volver aquí, porque esta es mi casa.

- Eso le diré a mi papá - Responde la niña.

Terminado el trabajo, aparece nuevamente la gente y una vez se llevan al niño congelado a Yarus Punta y otra vez desaparece. A la mañana siguiente, molesto le dice a la niña:

- Porque insisten en sacarme de mi casa. Nosotros somos tres hermanos. Uno se fue para el pueblo de Mosca allá por Huánuco y el otro al pueblo de Yarinacocha. Y yo me debo quedar aquí y no en Yarus Punta.

La niña le avisa a su papá y a la gente del pueblo que no le hacen caso. Hasta que una noche, el papá de la chica sueña con el niño que le revela:

- No me lleves a Yarus Punta. Hazme mi casa acá en Yacán, en Cantopuquio me voy a quedar, pero si ustedes me siguen llevando, me voy a ir a otro pueblo. Porque yo soy San Francisco, el patrón de tu pueblo.

Entonces, San Francisco se vino a vivir a Yacán, dejando Yarus Punta en ruinas, lo que hoy se puede apreciar. Ya en Yacán construyeron el pueblo. Y en Cantopuquio construyeron el templo. Luego acordaron hacer una fiesta, en nombre de san Francisco de Yarusyacán el 04 de octubre. Ese día es la fiesta de San Francisco porque dicen que la gente había visto ese día a san Francisco cabalgando en un caballo blanco que visitaba los pueblos de Yarusyacán. La fiesta lo celebraban todas las personas del distrito desde Chauyar hasta Machcán.

\section{Metodología y material}

La metodología empleada en la investigación fue la entrevista directa, la naturaleza de la investigación cualitativa así lo amerita. Visitamos los trece distritos de la provincia de Pasco para poder entrevistar y recoger la información de los propios residentes en los distritos, quienes a la vez se constituyen en el material del estudio porque con la narración oral de sus historias configuran el pasado y el imaginario de la memoria colectiva del pueblo pasqueño. 
Durante el tiempo del recojo de la información se fue sistematizando las respectivas historias y durante los meses de diciembre de 2019 y enero 2020, se sistematizó con la revisión bibliográfica especializada además del aporte analítico de los miembros del equipo investigador.

\section{Resultados}

Desde que los literatos pasqueños César Pérez Arauco y Zenón Aira Díaz, en los años setenta y ochenta, emprendieron la recopilación de la tradición oral pasqueña, no se ha realizado investigaciones al respecto, en tal sentido nuestra investigación construye en el presente, el discurso oral de las tradiciones de la provincia de Pasco con nuevas historias del acervo oral, guardado en la memoria colectiva de los pasqueños, creemos que es el factor relevante de la investigación, porque pone de manifiesto la historia pasqueña en el mundo globalizado de hoy. César Pérez Arauco, es uno de los primeros intelectuales en interesarse por rescatar la tradición oral pasqueña, nos muestra testimonios valiosos de la cultura oral cerreña. "Las historias huérfanas encontraron en César al padre, con él las quimeras se convirtieron en realidades, la oralidad en lectura, y la desnuda mitología cerreña encontró su ropaje. Todo ello se lo debe a la oralidad, lo reconoce en la dedicatoria y presentación de su libro Cuentos y leyendas de Pasco" (La Madrid, 2004, p, 10). De la misma manera Zenón Aira Díaz, escritor autodidacto, muestra en su libro Fantasmandino, historias orales de condenados y pishtacohs.

Las investigaciones realizadas por César Pérez Arauco, Zenón Aira Díaz y Daniel de la Torre Tapia, son trabajos que contrastan con nuestra investigación por varias razones: la primera se refiere a que las historias narradas por dichos investigadores son conocidas ya buen tiempo, las nuestras en su mayoría son inéditas, la segunda, en el caso de Daniel de la Torre su temática aborda historias de la minería y fantasmas y Zenón Aira tiene predilección por las historias de condenados y pishtacohs, las recopilaciones nuestras tienen temática distintas con historias disímiles, al respecto el trabajo de César Pérez se asemeja a nuestra investigación. Asimismo, nuestra investigación muestra los nombres de los informantes, la de ellos se desconoce la fuente nominal, que posiblemente lo tienen, pero que no lo han dado a conocer en su momento ni en sus textos, sin embargo, debemos manifestar nuestra gratitud y admiración a los mentados investigadores porque abrieron el camino de la investigación oral en Cerro de Pasco.

Los cuentos recogidos relacionados con la religión y que fueron transcritos para el I tomo de la Tradición oral de Pasco son la evidencia clara de la investigación, que presentamos a continuación:

\begin{tabular}{|c|l|l|l|}
\hline $\mathrm{N}^{\circ}$ & \multicolumn{1}{|c|}{ Cuentos religiosos } & \multicolumn{1}{|c|}{ Resumen } & Distrito \\
\hline 1 & Los milagros del tayta Nashaco & $\begin{array}{l}\text { Milagro del cristo nazareno frente a la } \\
\text { sequía }\end{array}$ & Pallanchacra \\
\hline 2 & El padre Cuto Vitula & $\begin{array}{l}\text { Un sacerdote irascible por ganar } \\
\text { adeptos para la iglesia }\end{array}$ & Pallanchacra \\
\hline 3 & San Miguelito & $\begin{array}{l}\text { Fundación de San Miguel de } \\
\text { Pallanchacra }\end{array}$ & Pallanchacra \\
\hline 4 & El rabo de mula del padre Vitula & $\begin{array}{l}\text { Un sacerdote que tiene comercio carnal } \\
\text { con una pobladora }\end{array}$ & Pallanchacra \\
\hline 5 & El santo Nashaco & $\begin{array}{l}\text { Deseo del cristo nazareno por } \\
\text { establecerse en Pallanchacra }\end{array}$ & Pallanchacra \\
\hline 6 & El niño San Francisco & $\begin{array}{l}\text { Fundación de San Francisco de Asís de } \\
\text { Yarusyacán }\end{array}$ & Yarusyacán \\
\hline 7 & $\begin{array}{l}\text { Cómo ganan los yarusyaquinos el } \\
\text { juicio }\end{array}$ & $\begin{array}{l}\text { San Francisco de Asís actúa como } \\
\text { abogado de la comunidad de } \\
\text { Yarusyacán }\end{array}$ & Yarusyacán \\
\hline
\end{tabular}




\begin{tabular}{|c|l|l|l|}
\hline 8 & La Virgen del granizo rojo & $\begin{array}{l}\text { Desobediencia de los viqueños por lo } \\
\text { que llueve granizo rojo }\end{array}$ & Vicco \\
\hline 9 & La Virgen abogada & $\begin{array}{l}\text { La Virgen María actúa como abogada } \\
\text { en favor de la comunidad de Huachón }\end{array}$ & Huachón \\
\hline 10 & San Pedro de Ninacaca & Desobediencia de los lugareños & Ninacaca \\
\hline
\end{tabular}

\section{Discusión}

Manolo Acosta (2018) en su artículo el Pensamiento crítico y las creencias religiosas sostiene que "una creencia religiosa asumida de manera acrítica trae consigo conductas sumisas que diluyen al sujeto que la experimenta", debemos comprender que la fe está al margen del pensamiento científico y por lo tanto crítico, al aceptar sus creencias como una verdad, eso es lo que ocurre con los pueblos que ponen toda su esperanza en la fe, por algo se dice que la fe mueve montañas y es aquí donde la religión juega un papel importante porque permite mantener la fe a lo largo de los años influenciado en la espiritualidad de los hombres como es el caso de los pobladores de la provincia de Pasco, quienes ponen de manifiesto su religiosidad en sus costumbres y tradiciones.

Parker (2006) en su estudio acerca de la religión y los pueblos indígenas en América Latina manifiesta que a pesar del sincretismo los pueblos mantienen sus creencias religiosas propias antes de la llegada de los españoles:

Los católicos, los evangélicos, los protestantes, los adventistas y otros movimientos tienen seguidores en muchas comunidades. No obstante, los sacerdotes de las religiones ancestrales y los chamanes indígenas, quienes han incrementado lenta pero consistentemente su número, aún realizan los rituales y mantienen las creencias mágico-religiosas que son, hasta cierto punto, capaces de contribuir en la reafirmación de una auténtica identidad étnica. (p. 90)

\section{Conclusiones}

La tradición oral de la provincia de Pasco tiene como tema diversos tópicos relacionados con los contextos de los distritos y pueblos, así sus historias testimonian aspectos relacionados con la agricultura, la religión, leyendas, entre otros. Lo curioso es que no se ha recogido mitos, los informantes no saben nada al respecto. $Y$ creemos, que los mitos se van perdiendo en la tradición oral de nuestros pueblos.

La representación religiosa en la tradición oral de la provincia de Pasco está presente en las historias de fundaciones de los pueblos como son los casos de San Francisco de Yarusyacán, de San Miguel de Pallanchacra y de San Pablo y San Pedro de Ticlacayán; en la representación de malos sacerdotes que aprovechándose de su investidura tuvieron comercio carnal con las mujeres de los pueblos pasqueños, como en la eterna lucha del bien y del mal. También, lo religioso trasciende más allá de una narración, su importancia radica en que las culturas prehispánicas eran dueñas de una religiosidad propia no solo por ser politeístas, sino por fieles creyentes en sus dioses, sin necesidad de tener al dios cristiano. El concepto de solidaridad y de reciprocidad son tan antiguos en el territorio peruano mucho antes de la conquista española, pero no solo el concepto, sino el hecho mismo de su aplicación en situaciones reales, ayudar al prójimo siempre ha sido una característica de la cultura andina. 


\section{Referencias bibliográficas}

Acosta, M. (2018). El pensamiento crítico y las creencias religiosas. Sophia, Colección de Filosofía de la Educación.

Alberti, G. y Mayer, E. (1974). Reciprocidad e intercambio en los Andes peruanos. Instituto de Estudios Peruanos.

Arguedas, J. M. (1987). Breve antología didáctica. Agua. Los Escoleros. Warma Kuyay, Oda al Jet ¿Qué es el folklore? Horizonte.

Carrión, R. (2005). El culto al agua en el antiguo Perú. Instituto Nacional de Cultura.

De la Torre, L. y Sandoval. C. (2004). La reciprocidad en el mundo andino. El caso del pueblo Otavalo. Abya - Yala.

Goya, J. (2002). Sobre la Hermenéutica Judía. Pensamiento y Cultura, núm. 5, 109-112.

La Madrid, PL., Arias, HL., Alvarado., J y Velásquez, P.(2004). A propósito de la oralidad en los cuentos y leyendas de Pasco de César Pérez Arauco. Revista de Literatura Diablo Blanco $\mathrm{N}^{\circ}{ }_{1}$, $10-12$.

López, J. y Suárez, A. (2016). Diversidad de creencias, devociones y prácticas religiosas en los asentamientos precarios de la Ciudad de Buenos Aires. Religiao Sociedade.

Manns, F. (2014). La Biblia: Revelación escrita y oral. Cuestiones Teológicas, Vol. 40, No. 94, 219-232.

Mansilla, H. (2007). Religión y razón como factores de complementación y colaboración. Revista de Filosofía. RF v.25 n.55.

Marzal, M. (1983). La transformación religiosa peruana.PUCP.

Marzal, M. (2005). Los santos y la transformación religiosa del Perú colonial. Pontificia Universidad Católca del Perú.

Parker, C. (2006). La religión y el despertar de los pueblos indígenas en América Latina. Alteridades, 10.

Salazar, D., La Madrid., PL, Muñoz, E., y Valentín, TF (2019). Tradición oral de la provincia de Pasco. Tomo I. San Marcos.

Sambarino, M. (1980). Identidad, tradición y autenticidad. Tres problemas de América Latina. Centro de Estudios Latinoamericanos Rómulo Gallegos.

(C) Los autores. Este artículo es publicado por la Horizonte de la Ciencia de la Unidad de Posgrado de la Facultad de Educación de la Universidad Nacional del Centro del Perú. Este es un artículo de acceso abierto, distribuido bajo los términos de la Licencia Atribución-No Comercial 4.0 Internacional.(https://creativecommons.org/licenses/by-nc/4.o/), que permite el uso no comercial y distribución en cualquier medio, siempre que la obra original sea debidamente citada. 